É com grande honra e satisfação que apresentamos o Dr. Weber Ursi, pois conhecemos toda a sua trajetória dentro da Ortodontia, desde os seus primórdios durante o curso de mestrado em nossa escola. Nessa época, já se destacava o seu brilhantismo na solução dos problemas clínicos ortodônticos, seu pendor para a docência e, especialmente, sua grande capacidade oratória e de redação.

Posteriormente, durante seu programa de doutorado, buscou aprimoramento científico adicional, candidatando-se e sendo aceito em um estágio "sanduíche" no Departamento de Ortodontia em Ann Arbor, Universidade de Michigan, com o eminente Prof. McNamara. Sua distinguida performance foi merecedora de uma elogiosa carta do Prof. McNamara ao Dr. Décio R. Martins, então chefe do departamento de Ortodontia, destacando-o como um dos melhores alunos que já teve. Dessa maneira, mantém com aquele distinto professor laços científicos e de amizade, que deram frutos a diversas publicações conjuntas. Subseqüentemente, complementou seu aprimoramento internacional na New York University, na área de Cirurgia Ortognática, onde também ministrou aulas em cursos de educação continuada.

Sua experiência em Ann Arbor culminou com a elaboração de sua tese de doutorado intitulada "Alteração clínica da face em crescimento: uma comparação cefalométrica entre os aparelhos extrabucal cervical, Frankel (FR2) e Herbst, no tratamento das más oclusões de Classe II, primeira divisão de Angle", onde estudou os efeitos de diferentes aparelhos funcionais no tratamento da má oclusão de Classe II. Com esse trabalho e outros subseqüentes nessa linha de pesquisa é considerado o ortodontista brasileiro que melhor conhece, teórica e clinicamente, os aparelhos ortopédicos funcionais fixos para a correção da má oclusão de Classe II, com reconhecimento internacional.

Ao retornar com tal distinção, foi aprovado como professor de Ortodontia na Faculdade de Odontologia de São José dos CamposUNESP, onde vem engrandecendo o Departamento com suas publicações internacionais e com sua visão objetiva da especialidade. Divide o tempo acadêmico com sua clínica particular, de forma que assim pode melhor transmitir sua experiência clínica aos seus alunos. Com todas essas qualidades é um orgulho para a Ortodontia brasileira e um exemplo a ser admirado e seguido.

\title{
Weber Ursi
}

- Graduação em Odontologia pela UEL (Universidade Estadual de Londrina) em 1982.

- Mestrado em Ortodontia pela Faculdade de Odontologia de Bauru - USP, 1986-1989.

- Visiting-fellow, University of Michigan, 1990-1991.

- Orthodontic Fellow in Orthognathic Surgery, New York University, 1991-1992.

- Doutorado em Ortodontia pela Faculdade de Odontologia de Bauru - USP, 1989-1993.

- Professor da Faculdade de Odontologia de São José dos Campos, UNESP, desde 1992

- Consultório particular em São José dos Campos/SP, desde 1992.

- Email para contato weberurs@iconet.com.br

É casado com Maura Leão, sócia e executiva do Yazigi Travel. Os dois vivem em São José dos Campos, com seus filhos Tomás (13) e Gabriel (11). Weber e Maura são sócios mantenedores da Esfera Escola Internacional, a primeira escola bilíngüe de São José dos Campos, desde 2003.

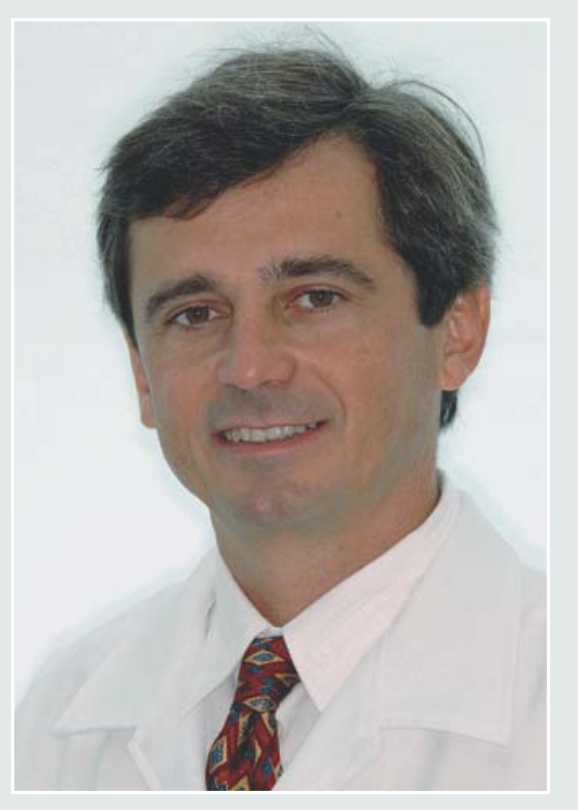

1) Baseado na sua experiência e nos seus artigos publicados nas revistas da Dental Press (1999 e 2000) e no AJODO (2001), como você aborda, atualmente, a Classe II em crescimento: Frankel, Bionator, extrabucal ou Herbst? Roberto Brandão

Caro Prof. Dr. Roberto Brandão, é com gran- de respeito e admiração pela sua estatura como professor, pesquisador e clínico que vou procurar responder sua pergunta. Com o passar dos anos - nossos e do conhecimento científico em geral - existe uma tendência a uma sedimentação do conhecimento e das experiências clínicas. Esta depuração nos leva à escolha de determinadas te- 
rapias que são mais eficazes, além de eficientes. Não se questiona que os aparelhos de Frankel e Bionator tenham suas indicações e, quando encontram condições favoráveis de crescimento e colaboração por parte do paciente, os resultados são notáveis. Infelizmente, nem sempre estas condições se apresentam num mesmo paciente, e os resultados ficam aquém dos esperados. Estima-se que somente $55 \%$ dos pacientes usam os aparelhos removíveis conforme são prescritos. O que se faz com os outros $45 \%$ ? Neste aspecto, uma opção que talvez não tenha a qualidade de resultado isolado que o Bionator ou o Frankel apresentam pode se mostrar uma alternativa que, na média de pacientes tratados consecutivamente, atinge resultados altamente positivos e sistemáticos. É melhor se tratar 5\% com resultados excepcionais ou $95 \%$ com resultados muito bons? Obviamente que a resposta profissional a esta questão é de cunho pessoal, mas nossos sufragistas são os pacientes que, quando satisfeitos, nos indicam outros - e a sua percepção do resultado, não a nossa. A figura 1 exemplifica e resume minha abordagem do tratamento do Padrão II. A utilização de uma ou outra opção dependerá do estágio de maturação do paciente. Na dentadura mista, a maioria dos pacientes (casos com pequena discrepância) é tratada somente visando a correção do componente transverso (disjunção). Os casos mais severos são tratados com Ortopedia Funcional dos Maxilares (Twin-block) ou splint de Thurow. A utilização do extrabucal é ainda imperativa, quando na com-

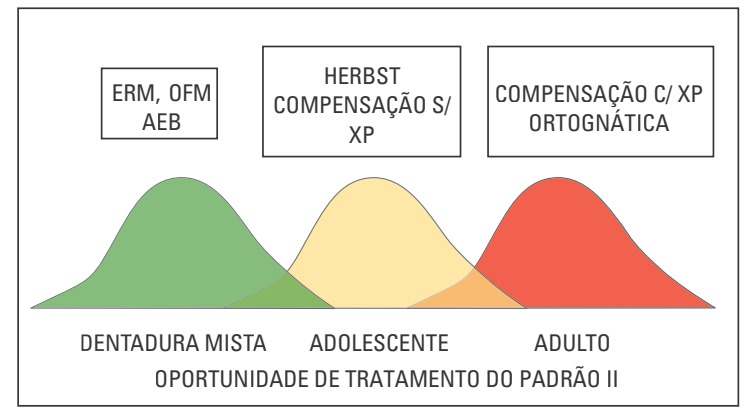

FIGURA 1 - Representação das possibilidades de tratamento, segundo concepção embasada em evidências científicas, do Padrão II, de acordo com a maturidade do paciente (adaptado e modificado de PANCHERZ ${ }^{5}$ ). posição da má oclusão exista um componente esquelético vertical significante, o que praticamente eliminaria qualquer efeito positivo de um avanço mandibular, mesmo que cirúrgico, se feito isolado. Com relação à época de sua utilização, entretanto, deve-se ter em mente que o crescimento maxilar não acompanha a mesma curva de crescimento da mandíbula. O crescimento mandibular acompanha a curva de crescimento geral, ou estatural, cuja aceleração maior se dá na adolescência. Em função de sua posição biomecânica e funcional, a maxila, entretanto, é influenciada pelas curvas de crescimento neural e estatural, apresentando um comportamento menos acentuado na adolescência. Em vista disto, a oportunidade para o uso das forças extrabucais, neste conceito, seria antes do surto de crescimento, a partir dos 8-9 anos de idade, por 10-12 horas ao dia, até a correção da má oclusão e, após isto, por 8 horas ao dia, como contenção, até a erupção dos segundos molares permanentes. Por inúmeros motivos, o modelo ideal seria o splint de Thurow, que permite, ao mesmo tempo, o controle vertical e sagital do crescimento da maxila, o ajuste de suas dimensões transversais à mandíbula e libera a expressão do crescimento mandibular, com rotação antihorária, melhorando sua projeção anterior. Casos excepcionais com discrepâncias esqueléticas acentuadas, com risco de fraturas de incisivos e com pouca colaboração, são tratados com mecânica Tip-edge e elásticos de Classe II, mesmo na dentadura mista. $\mathrm{Na}$ dentadura permanente em pacientes em crescimento, utilizo o aparelho de Herbst para diminuir a discrepância esquelética, ou mesmo ao final do crescimento, como método para aumentar as compensações pré-existentes. Como se pode ver, dos 4 aparelhos citados em sua pergunta, apenas 2 fazem parte, atualmente, de meu armamentário e, pelo menos na dentadura mista, o uso do extrabucal é mais freqüente que a Ortopedia Funcional dos Maxilares.

2) Há alguns anos, quando você começou a utilizar o aparelho de Herbst, pouco se ouvia falar dele no Brasil. Hoje, ele tem sido bastan- 
te utilizado no tratamento da Classe II. Quais são as maiores dificuldades que o ortodontista clínico enfrenta quando começa a utilizá-lo? Qual a sua opinião em relação ao uso deste aparelho em pacientes adultos jovens? Alexandre Moro

Caro Prof. Moro, a pergunta vinda de um expert no assunto carrega consigo um peso maior, por isso procurarei ser o mais esclarecedor, dentro de minha óptica. Com relação à primeira parte de sua pergunta, acredito que atualmente, com o acesso às informações na internet, à literatura clínica, às informações das empresas de materiais ortodônticos e à disponibilidade dos próprios materiais, um ortodontista experiente precisa de poucas horas para dominar seu manejo clínico. É um aparelho com uma curva de aprendizado rápida, mas altamente dependente da qualidade do material utilizado, do laboratório e da habilidade do clínico. Após vencer a insegurança inicial (depois de uns 5 casos), o tempo de cadeira para sua instalação e ajustes é igual a duas vezes o que se gasta com um disjuntor de Haas. Com relação à escolha do mecanismo, hoje existem inúmeras opções, de diversos fornecedores (Ormco, GAC, TP, Dentaurum, American Orthodontics, etc). Sua escolha, obviamente, passa pelo critério de custo/benefício, sendo que, normalmente, "o caro não é o que custa muito, mas o que vale pouco". Uma boa opção são os sistemas de menores dimensões, de bordas arredondadas e que permitem movimentos amplos de abertura e lateralidade, com sistemas de acoplamento simplificados. O próximo passo é a seleção da ancoragem que vai suportar o aparelho: bandas, coroas de aço, armações de cromo-cobalto ou mesmo de resina acrílica. Caso a escolha recaia sobra as bandas, elas devem ser extra-resistentes, com reforço de solda em seu entorno. A TP Orthodontics ${ }^{\mathrm{TM}}$ tem uma linha de bandas extra-reforçadas, mas que são
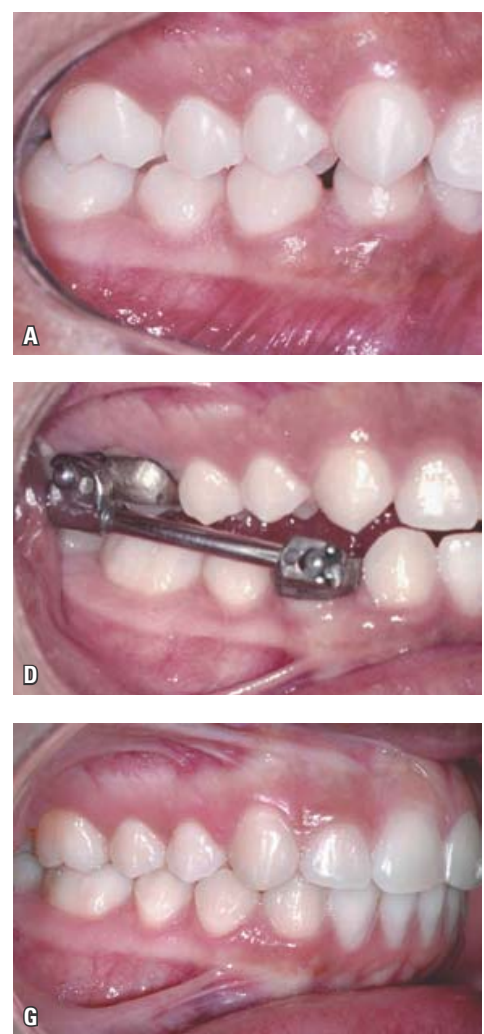
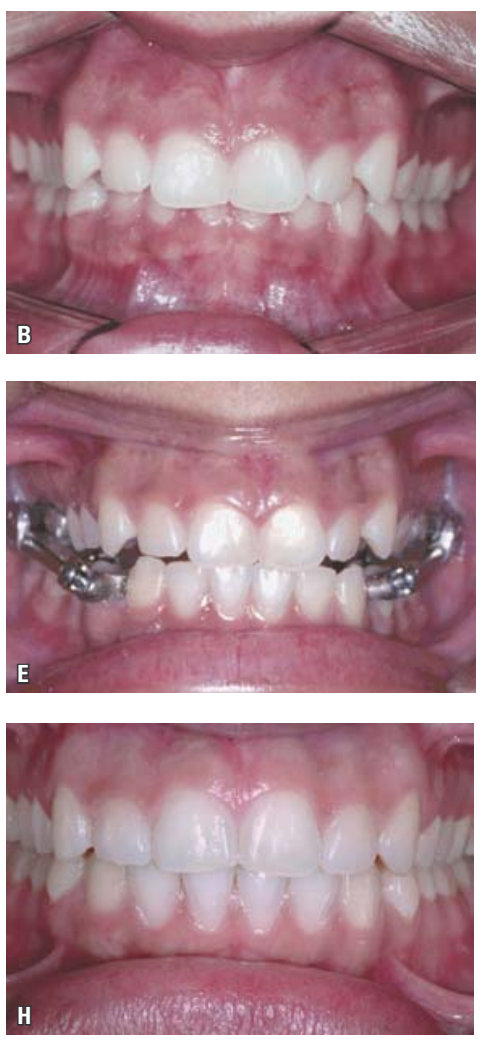

FIGURA 2 - A, B, C) Pré-tratamento; D, E, F) com aparelho de Herbst; G, H, I) pós-tratamento.
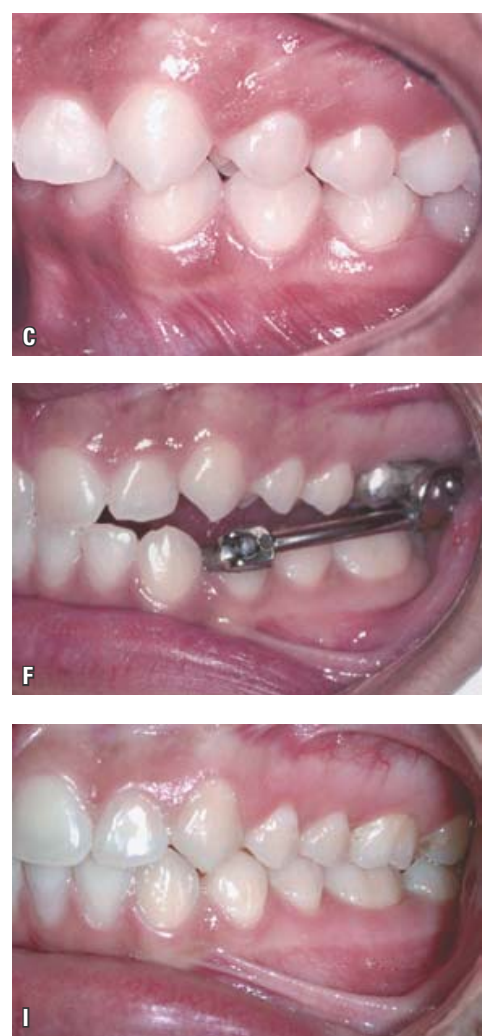
ofertadas apenas para os primeiros molares e não para os pré-molares (Fig. 2). Se a opção forem as coroas, além de serem mais resistentes às fraturas, normalmente são mais retentivas. A opção com armação do cromo-cobalto, proposta por Pancherz ${ }^{5}$, obviamente dependerá da interação do ortodontista com um protético que tenha experiência em armações de próteses parciais removíveis, necessitando de uma moldagem mais exata e da instalação do aparelho em, no máximo, duas semanas após a moldagem.

Com relação à segunda parte de sua pergunta, sobre o uso deste aparelho em pacientes adultos jovens, creio que todos que atuam nesta área se baseiam nas informações de Ruf e Pancherz ${ }^{6}$ sobre o assunto, que apresentam resultados surpreendentes e animadores com relação a esta abordagem. Creio que já existam informações suficientes na literatura que nos permitam ampliar nosso envelope de utilização deste aparelho em faixas etárias que, normalmente estariam sendo tratadas com exodontias compensatórias ou com cirurgia ortognática. Por formação e índole - e sempre pensando em cada paciente individualmente, e não nas médias de populações - tendo a ser conservador e não usar meus pacientes como experimentos pagantes. Portanto, ainda não utilizei este protocolo em pacientes do gênero feminino com mais de 18 anos e do masculino com mais de 20, sendo os resultados, nestes casos, em minha experiência, bastante promissores. Por outro lado, as compensações dentoalveolares obtidas e as possiveis adaptações no binômio côndilo/fossa mandibular - desde que demonstradas por vários grupos de pesquisadores, utilizando métodos de imagem como tomografias computadorizadas e ressonância magnética - podem vir a mudar este paradigma nos próximos anos, sendo possível que o envelope de segurança para uso do aparelho de Herbst possa vir a ser expandido.

Como se pode ver na figura 1, existem áreas de interseção (grey areas) onde os limites das opções de tratamento se sobrepõem. Justamente nestes pacientes é que um maior cuidado deve ser tomado, para não incorrer em erros irreversíveis de julgamento como, por exemplo, a tentativa de compensação com exodontias em casos com indicação cirúrgica.

3) Os aparelhos ortopédicos funcionais são capazes de alterar o crescimento mandibular além de seu potencial genético? Quais são as alterações dos mesmos no comprimento mandibular durante o tratamento, durante $\circ$ período de contenção e em longo prazo? Guilherme Janson

Caríssimo professor Guilherme. Fique muito feliz pelo senhor ter coordenando esta entrevista. Você é um orgulho para a Ortodontia brasileira e sua produção científica em periódicos internacionais o torna figura ímpar em nosso cenário. Sou "cria", como aluno, do Departamento de Ortodontia da FOB-USP, a quem devo quase tudo que atingi e, nas figuras dos professores Décio Rodrigues Martins, Renato Rodrigues de Almeida, José Fernando Castanha Henriques, Marcos Roberto de Freitas, Arnaldo Pinzan e a sua pessoa, só tenho a agradecer, pela oportunidade que me foi confiada. Vou tentar responder suas perguntas de forma didática, daquilo que entendo que seja o "state of the art and the essence of the science". A primeira parte de sua pergunta remete a dois paradigmas que regem as opiniões sobre este assunto. O paradigma genômico foi cunhado a partir dos trabalhos de Sicher e de Brodie que, de maneira categórica, afirmaram que não era possível influenciar o crescimento craniofacial além de seu "potencial genético", embora seja muito difícil definir ou mensurar este potencial. Neste paradigma, o côndilo é o centro de crescimento, condicionado e regulado a partir do código genético herdado, sofrendo pequena influência dos fatores epigenéticos locais. A cartilagem condilar, neste enfoque, possui "tissue separating capacity", sendo categorizada como cartilagem primária de crescimento. Desta forma, o deslocamento da mandíbula é inteiramente originado do deslizamento do côndilo para trás e para cima (com variação de direções, em casos extremos). A partir dos trabalhos de Carlson, McNamara, Petrovic e Moss, derivou-se 
um outro paradigma, chamado Funcional, que aponta o côndilo como sítio de crescimento, com características de crescimento e adaptação compensatórias às demandas funcionais da cápsula buconasal. Segundo inúmeras pesquisas em animais experimentais, a cartilagem condilar não teria um comportamento semelhante às cartilagens primárias, encontradas nas epífises dos ossos longos ou mesmo da base craniana, sendo caracterizada como uma cartilagem secundária, não presente no esqueleto cartilaginoso primário. Esta diferença filogenética explica as diferenças no comportamento das cartilagens da base craniana e da condilar, sendo a principal a possibilidade da mediação na taxa de proliferação celular da camada pré-condroblástica, quando a última é submetida a determinadas alterações biomecânicas. Portanto, a curto prazo, em uma parte do período de uso destes aparelhos, mas provavelmente não durante todo o tempo em que são utilizados, é sem dúvida possível esta mediação, que alguns chamam de estímulo ou "hipoteca" de crescimento, em que as taxas de proliferação celular são aumentadas, e o que talvez seja mais importante, a direção do crescimento condilar é influenciada. Esta alteração na direção do deslizamento condilar, mais para anterior ou posterior que a original, é que vai propiciar uma melhor ou pior resposta do deslocamento total mandibular, particularmente, da projeção do mento. A quantidade deste estímulo é menos importante que a direção em que ele se manifesta (Fig. 3) ${ }^{1}$. Conforme os dentes vão se contatando nas novas posições, a musculatura vai retornando ao seu comprimento original de trabalho e a relação côndilo-fossa se reestabelecendo, este estímulo diminui a níveis iguais ou até menores que em indivíduos não tratados. Com o passar dos anos, o impacto mais significativo da terapia com aparelhos funcionais (a projeção mandibular) se dilui, de modo que o perfil assume uma condição mais convexa, intermediária entre a promessa do avanço e a realidade da adaptação morfofuncional. Isto invalida o uso destes aparelhos? Ao meu ver, de modo algum, uma vez que tal fato ocorre em todos os tratamentos ortodônticos, ortopédicos e

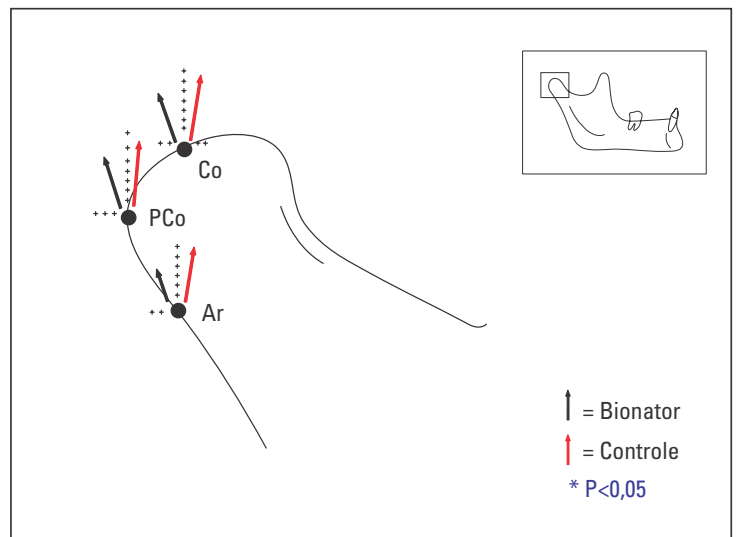

FIGURA 3 - Crescimento condilar após 1 ano de tratamento, para os grupos controle e bionator (cada sinal + equivale a 0,5mm). Retirado, com permissão, de ARAUJO, A.; BUSCHANG, P.; MELO, A. C. ${ }^{1}$

cirúrgicos, em maior ou menor grau. Sistematicamente, o que observa é um retorno gradativo ao padrão morfogenético original, mas com uma ressalva: na maioria dos casos, existe uma estabilidade oclusal satisfatória, tanto estática quanto funcional. Em minha prática clínica, a utilização de aparelhos ortopédicos funcionais na dentadura mista diminuiu nos últimos 10 anos, em função do aumento do uso do aparelho de Herbst no início da dentadura permanente, mais próximo do surto de crescimento pubescente. Sem dúvida, a melhor combinação para maximizar resultados ortopédicos em pacientes Padrão II é o tratamento adequado e crescimento em sua plenitude, nada se comparando a este dueto ${ }^{4}$.

4) Qual a sua opinião em relação aos distalizadores intrabucais, quanto ao custo-benefício do tratamento? Os efeitos colaterais são insignificantes? São eficientes para a correção da má oclusão de Classe II completa? Guilherme Janson

Existe uma frase que explica bem minha opinião sobre os distalizadores: "só se enxerga o que se conhece". Há 10 anos, houve, com a participação decisiva do Dr. James Hilgers, o boom dos distalizadores, particularmente do Pêndulo e sua família. Não havia periódico ortodôntico que não tivesse um artigo com um "novo" aparelho, mas com os mesmos mecanismos: um ativo - para "dis- 
talizar" os molares - e um reativo - mesializando todos os dentes a partir dos segundos pré-molares. Os nomes podem ter variado, assim como as perdas de ancoragem, mas todos, sistematicamente, apresentavam um problema em comum: o aumento da sobressaliência conforme o espaço entre o primeiro molar e os pré-molares aumentava. Muitos erros foram cometidos na época, com casos que poderiam ser descritos em termos teatrais, sendo a comédia da distalização seguida da tragédia da recidiva, uma vez que os primeiros molares teimavam em voltar às suas posições originais, virtualmente abaixo da key-ridge, como que vingando os preceitos originais de Angle, quanto à sua imutabilidade. Os efeitos colaterais só podiam ser eliminados, em muitos casos, com extrações dentárias. O grande problema que vejo com os distalizadores não é o conceito em si, mas a falta de critério para sua utilização. Mais uma vez, a mecânica ortodôntica subverteu a ordem natural - vindo antes do planejamento adequado - e, como sempre ocorre na natureza, ela não se defende, apenas se vinga. Tentativas heróicas de tratamentos de pacientes Padrão II, com relações molares com $7 \mathrm{~mm}$ ou mais de erro, foram realizadas de maneira afoita e com mínimas chances de sucesso. Com o passar dos anos, o conhecimento mais profundo dos efeitos positivos e negativos dos distalizadores tornou patente que sua utilização deve se restringir a casos de pacientes com relações molares de Classe II, sem envolvimento esquelético e facial. Seu lugar no armamentário ortodôntico ainda existe, mas somente os utilizo para correções de meia cúspide (Fig. 4) ou casos de distalização unilateral, como nas Classes II, subdivisão, com desvios de linha média localizados no arco superior, em relação à linha média facial. Infelizmente, a maioria dos desvios de linha média, nestas más oclusões, se encontra no arco inferior, o que contra-indica o seu uso.

5) Como as alterações a longo prazo nos tecidos moles faciais afetam seu diagnóstico e sua escolha na utilização de aparelhos fixos e/ou ortopédicos? Alexandre Moro
Obviamente que as alterações a longo prazo devem fazer parte de todo planejamento ortodôntico, particularmente naqueles casos onde o impacto da correção dentária possa ter um efeito deletério na estética facial do paciente. Com relação aos aparelhos ortopédicos, em particular, os ganhos advindos de seu uso, normalmente, se perdem em quantidade, mas não em qualidade. O que significa esta aparente dicotomia? As avaliações cefalométricas milimétricas mostram alguma perda, com uma tendência de retorno à projeção inicial do mento, particularmente com relação à linha queixo/pescoço. Ocorre que, ao mesmo tempo, os pacientes sofrem modificações e remodelações no tecido mole facial, decorrentes do crescimento/desenvolvimento e, mais tarde, do envelhecimento. Estas mudanças diluem as perdas e se confundem com elas, de modo que o paciente não discrimina sua convexidade facial, mas sim a presença ou não da sobressaliência dos dentes anteriores. Seu parâmetro de sucesso de tratamento é o overjet, desde que seus "social six" (dentes anteriores com impacto estético e social) estejam corrigidos, dificilmente ele apresentará alguma queixa neste sentido. Não me recordo de nenhum caso tratado com o aparelho de Herbst em que o paciente tenha manifestado sua insatisfação com o resultado estético facial final. Isto, provavelmente, ocorre porque o padrão Classe II é de manifestação hereditária, com penetrância variável. Portanto o espectro variável desta má oclusão se encontra presente em outros membros da família, tornandoos parecidos entre si, como normalmente parentes consangüíneos o são. Minha experiência é que o perfil final do paciente - ao final de todo tratamento com Ortopedia Funcional ou Mecânica (Herbst), seguido do detalhamento oclusal com aparelhos fixos - é intermediário entre seu estado inicial (pré-tratamento) e o perfil obtido numa relação de mordida construtiva topo-a-topo (Fig. 5, 6).

Com relação a outros tratamentos, como casos limítrofes para exodontias, normalmente uso como referência a combinação de 3 fatores: padrão facial/discrepância de modelos/sobremordida. Como em qualquer outra decisão na área mé- 

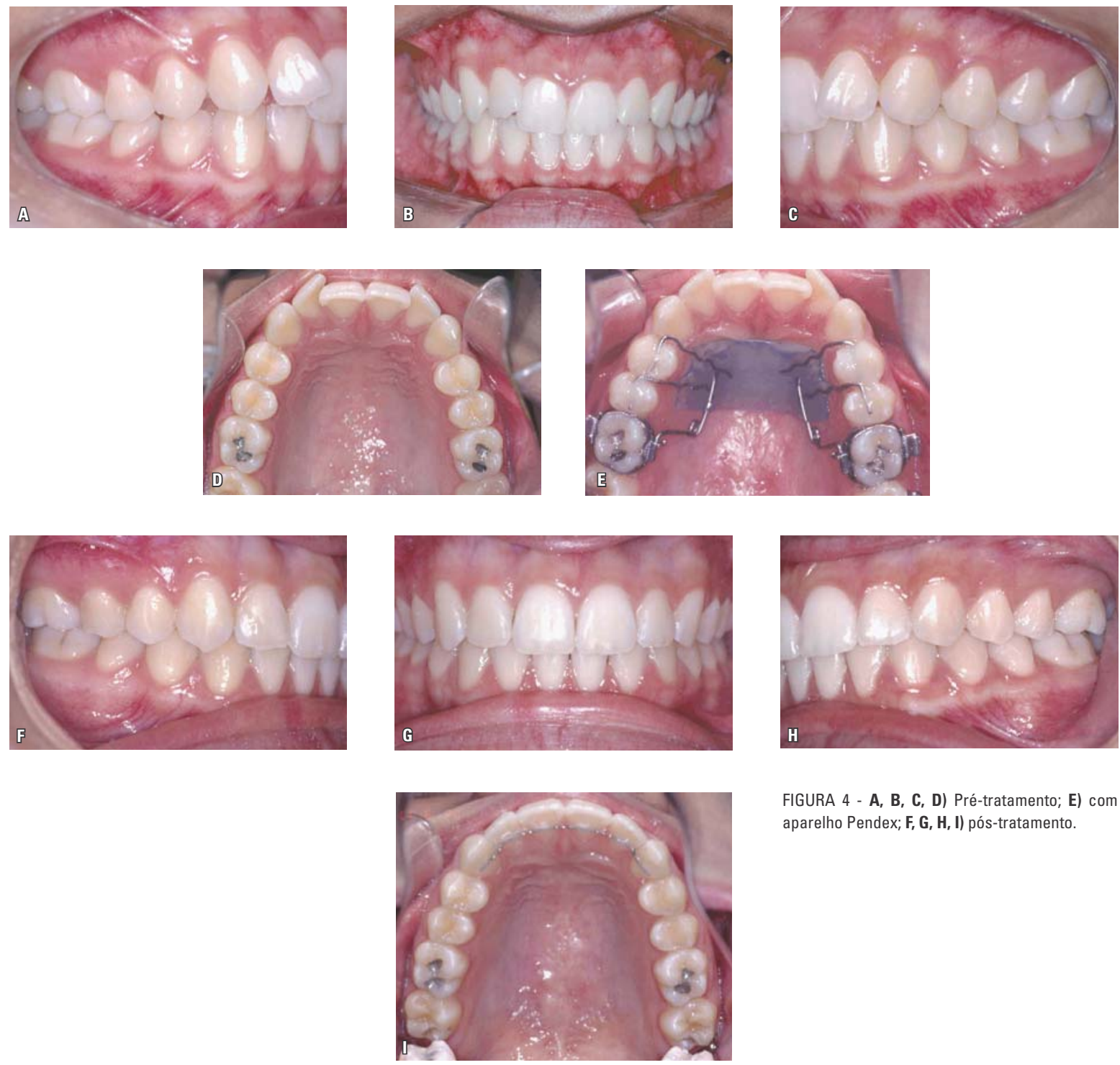

FIGURA 4 - A, B, C, D) Pré-tratamento; E) com aparelho Pendex; F, G, H, I) pós-tratamento.

dica, quando duas opções são possíveis, se escolhe sempre a terapia que seja menos invasiva, mesmo ao custo de possíveis recidivas ou instabilidades. Pacientes com alguma biprotrusão facial aos 12-14 anos, com o envelhecimento dos tecidos esqueléticos e tegumentares, se tornam menos protrusos, conforme os anos passam. Um exemplo clássico disto é a presença de selamento labial, de cunho diretamente proporcional à idade. Num grupo de crianças de 9 anos de idade, a freqüência de falta de selamento é muito maior do que o mesmo gru- po apresentará aos 25 anos de idade.

Conforme envelhecemos, as alterações no tecido tegumentar tornam os lábios mais finos, diminuindo a altura do vermelhão - em função da perda de tonicidade da pele e da musculatura da expressão facial, existe um aparente aumento do terço inferior da face, ocorrendo um abaixamento da linha interlabial em relação aos dentes, diminuindo a exposição destes em repouso. Além disto, as colunas do filtro se tornam menos evidentes, o arco de cupido diminui, ocorre o caimento 

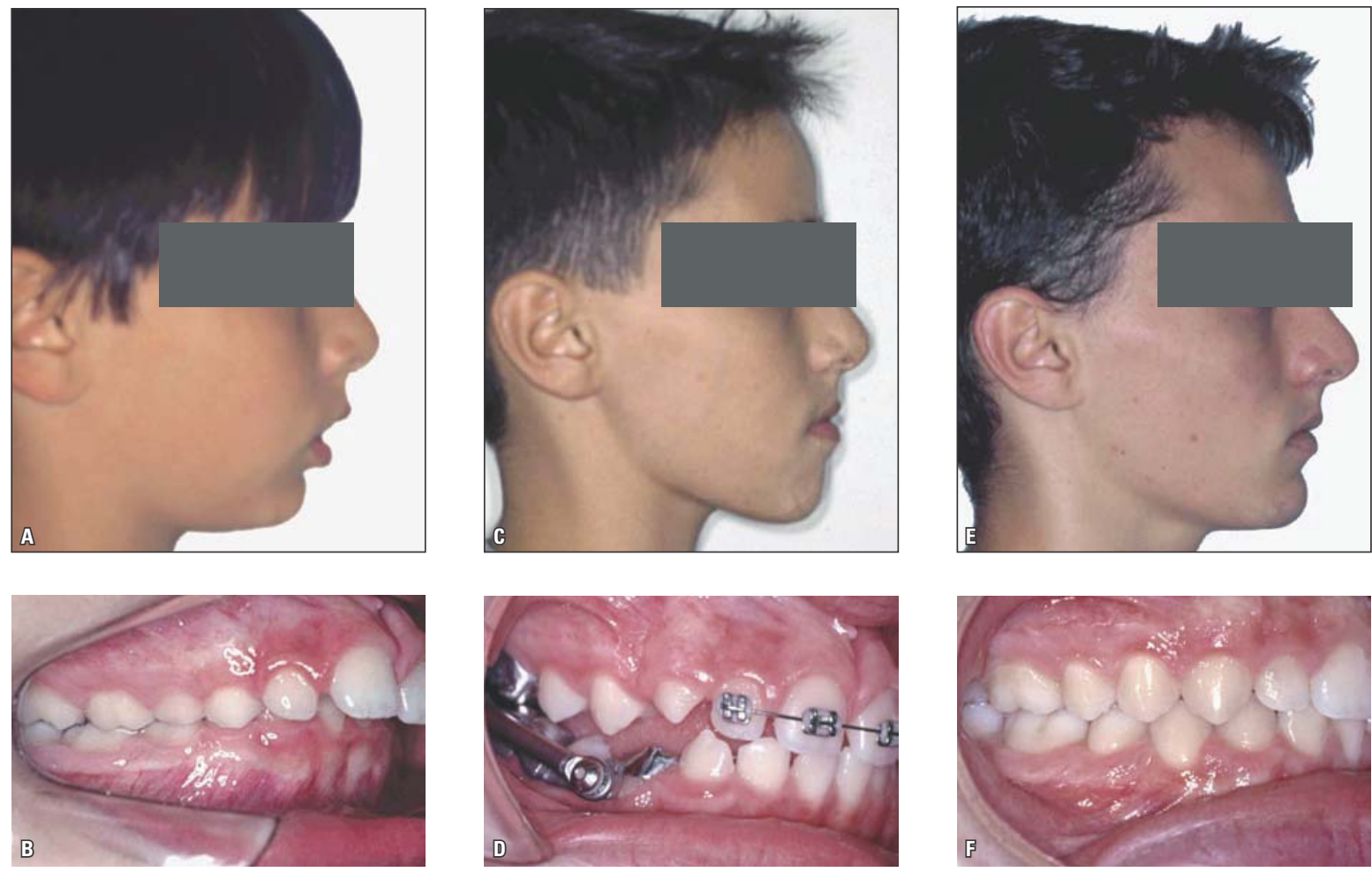

FIGURA 5 - A, B) Pré-tratamento na dentadura mista; C, D) com aparelho de Herbst; E, F) pós-tratamento.
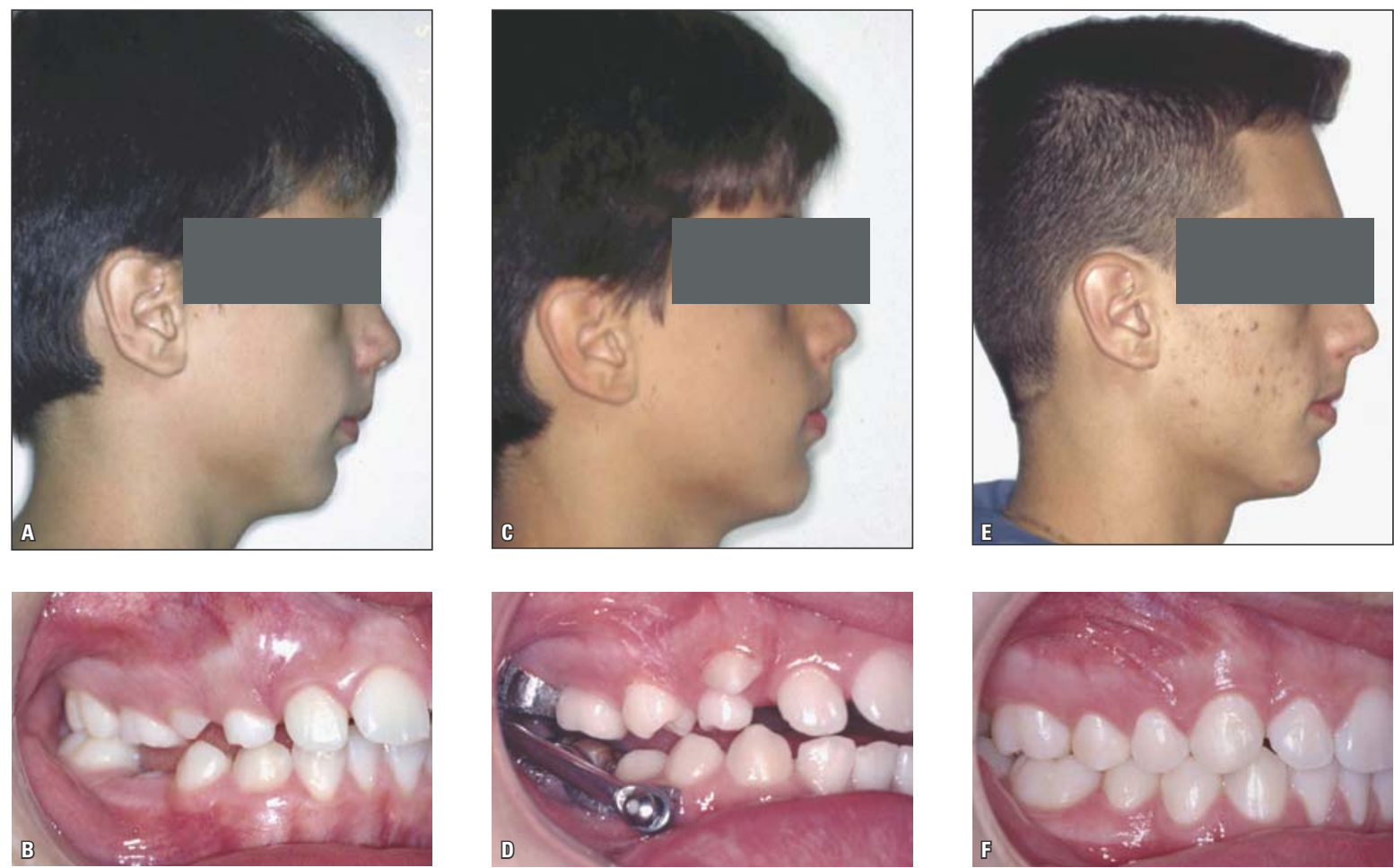

FIGURA 6 - A, B) Pré-tratamento na dentadura mista; C, D) com aparelho de Herbst; E, F) pós-tratamento. 


\section{EXPOSUCูÃA DOS INCISIVOS}

\section{5 - 60 anos (exposição em mm)}

\begin{tabular}{|ccc|}
\hline idade & I.S. & I.I. \\
$<30$ & 3,4 & 0,5 \\
$30-40$ & 1,6 & 0,8 \\
$40-50$ & 1,0 & 2,0 \\
$50-60$ & 0,5 & 2,5 \\
$>60$ & 0,0 & 3,0 \\
\hline
\end{tabular}

FIGURA 7 - Decréscimo de exposição dos incisivos superiores, em relação aos lábios superiores, à medida que envelhecemos (Fonte: VIG, BRUNDO ${ }^{8}$ ).

das bochechas e da região submental, além do abaixamento das comissuras labiais. Conforme os dados da figura 7, de Vig e Brundo ${ }^{8}$, pode-se observar uma exposição decrescente dos incisivos superiores e crescente dos inferiores, à medida que envelhecemos. Se somarmos a este fator o crescimento contínuo do nariz e do mento, fica óbvio que, se existe uma tendência no amadurecimento da espécie, é para uma diminuição da exposição dos dentes. Portanto, deve-se ter cuidado redobrado antes de decidir pela realização de exodontias, em casos em que a protrusão labial não for evidente.

Obviamente que a decisão pela não-extração não pode ser baseada unicamente neste parâmetro, ela só é aceitável se for possível a obtenção de uma oclusão estática e funcionalmente adequada, com sobremordida e sobressaliência suficientes para uma oclusão mutuamente protegida. Não se pode atribuir à exodontia de pré-molares "per se" o desenvolvimento de perfis faciais achatados (Dished in). Stephens et al. ${ }^{7}$ demonstraram claramente que se, ao final do tratamento com exodontias de pré-molares, a posição labial estiver dentro da aceitabilidade dos parâmetros de normalidade, os resultados, 15 anos depois, serão tão bons quanto os de casos sem exodontias. Uma das linhas de referência mais adequadas para tal avaliação é a linha SN-Pog' (Subnasal ao pogônio tegumentar), onde os lábios superiores devem estar ligeiramen- te à frente e os inferiores coincidentes com ela. Portanto, o cuidado maior não é com relação à realização ou não da exodontia, mas sim com a posição dos lábios ao final do tratamento, qualquer que seja o opção realizada ${ }^{3}$.

\section{6) Qual o seu protocolo para a disjunção palatal, considerando o tipo de aparelho, a idade do paciente e a freqüência de ativa- ções? Roberto Brandão}

Creio que, mais uma vez, temos que considerar mais as evidências científicas atuais que nossos dogmas aprendidos por experiência própria. $\mathrm{O}$ tipo de aparelho não é uma preferência do profissional, mas é determinado pelas necessidades e idades dentária e biológica do paciente. Inicialmente, minha educação ortodôntica pela FOB-USP me expôs ao uso do disjuntor clássico de Haas, mais tarde, com McNamara, ao disjuntor com cobertura oclusal e mais recentemente, às vantagens higiênicas do disjuntor Hyrax. Como equacionar a indicação destes três aparelhos? A resposta está no grau de interdigitação das hemi-maxilas, no componente vertical presente (sobremordida ou mordida aberta) e na necessidade do uso de tração extrabucal (Classe II e principalmente Classe III).

A figura 8 ilustra as indicações do tipo de disjun-

\begin{tabular}{|c|c|c|c|c|}
\hline dentadura & & Haas & encapsulado & Hyrax \\
\hline decídua & $\begin{array}{l}\text { MCP e/ou ATR MAX } \\
\text { C/ SOB normal }\end{array}$ & + & + & +++ \\
\hline decídua & $\begin{array}{l}\text { MCP e/ou ATR MAX } \\
\text { c/ MCA e/ou MAA }\end{array}$ & + & +++ & + \\
\hline decídua & $\begin{array}{c}\text { MCP e/ou ATR MAX } \\
\text { c/ SOB }\end{array}$ & + & - & +++ \\
\hline mista & $\begin{array}{l}\text { MCP e/ou ATR MAX } \\
\text { c/ SOB normal }\end{array}$ & +++ & ++ & +++ \\
\hline mista & $\begin{array}{l}\text { MCP e/ou ATR MAX } \\
\text { c/ MCA e/ou MAA }\end{array}$ & + & +++ & + \\
\hline mista & $\begin{array}{c}\text { MCP e/ou ATR MAX } \\
\text { c/ SOB }\end{array}$ & +++ & - & +++ \\
\hline permanente & $\begin{array}{c}\text { MCP e/ou ATR MAX } \\
\text { c/ SOB }\end{array}$ & +++ & - & - \\
\hline permanente & $\begin{array}{l}\text { MCP e/ou ATR MAX } \\
\text { c/ LATEROG }\end{array}$ & + & +++ & - \\
\hline permanente & $\begin{array}{l}\text { MCP e/ou ATR MAX } \\
\text { C/ MCA e /ou MAA }\end{array}$ & ++ & +++ & - \\
\hline
\end{tabular}

FIGURA 8 - MCP: mordida cruzada posterior; ATR MAX: atresia de maxila MCA: mordida cruzada anterior; MAA: mordida aberta anterior; SOB: sobremordida profunda; LATEROG: laterognatismo. 
tor recomendado para as diversas situações clínicas e o estágio de maturidade dentária/esquelética do paciente. $\mathrm{O}$ disjuntor de Haas teria sua melhor indicação em casos de mordida cruzada posterior nas dentaduras mista e permanente, com sobremordida normal ou profunda, em função de sua grande rigidez e apoio contra a mucosa palatina. O disjuntor encapsulado estaria melhor indicado para casos de mordida aberta anterior e mordida cruzada anterior nas três dentaduras, em função da desoclusão imediata à sua colocação e efeito do Bite-block sobre os dentes posteriores. Adicionalmente estaria recomendado para casos de laterognatismo em pacientes adolescentes com desvios funcionais e algum comprometimento esquelético. Para o tratamento de mordidas cruzadas anteriores com comprometimento esquelético (Classe III), a associação com tração reversa é mais eficiente ao final da dentaduras decídua ou início da permanente. Finalmente, o disjuntor do tipo Hyrax teria suas melhores indicações nas atresias de maxila, com mordida cruzada posterior ou não, nas dentaduras decídua e mista, uma fez que sua rigidez não é suficiente para suportar o acúmulo de forças necessárias para a disjunção em pacientes no final do adolescência, com grandes chances de inclinações indesejáveis da unidade de ancoragem.

Com relação ao padrão de ativação, o mesmo deve respeitar a idade esquelética do paciente. Normalmente, na dentadura decídua e mista, 1/4 de volta $(0,25 \mathrm{~mm})$ por dia é suficiente para provocar a disjunção maxilar, não sendo necessária uma ativação mais agressiva, conforme demonstrado por Chagas et $\mathrm{al}^{2}{ }^{2}$ À medida que o paciente vai se tornando adolescente, a resistência à disjunção aumenta e o padrão de ativação necessariamente é mais rápido - com $3 / 4$ de volta diários - sendo um quarto de volta a cada 8 horas. Obviamente que, à medida que o paciente for avançado mais em idade esquelética, os riscos de danos aos tecidos de suporte aumentam, particularmente nos pacientes que já apresentam uma tábua óssea vestibular mais delgada. A idade ideal para a disjunção maxilar, nesta óptica, é na dentadura mista, diminuindo o risco de danos e otimizando o procedimento.
7) Você concorda com a afirmação de que o ortodontista brasileiro se preocupa mais com o tipo de braquete que ele usa, do que com o embasamento científico dos procedimentos que ele realiza? Além disso, ele não avalia o custo-benefício dos tratamentos, principalmente aqueles realizados na dentadura mista? O que contribui para essa situação? Alexandre Moro

O triste da resposta é que a maioria nem conhece bem o motivo de sua preocupação. A maioria não sabe os valores da prescrição que usa e, o que é pior, nem sabe porque a usa. Imagine um médico prescrevendo medicamentos sem conhecer o que está na sua composição! Há 10 anos atrás, eu recebia folders de cursos de Especialização, anunciando a técnica utilizada (Straight-wire, Edgewise, Ricketts, Bioprogressiva, etc), o que já era constrangedor, principalmente para explicar para um colega do exterior. Agora recebo folders nominando os braquetes utilizados, como se o diferencial do ortodontista se resumisse aos braquetes que utiliza, diminuindo a importância da formação do profissional. Os alunos dos cursos de Ortodontia são, em última análise, vítimas de seus professores, sendo alimentados com os conhecimentos que seus mestres reproduzem, sem haver, muitas vezes, um questionamento de suas escolhas. Alguns cursos são atrelados a interesses comerciais, criando uma tendenciosidade nada saudável na escolha das mecânicas a serem utilizadas. No AJODO de junho de 2007, o Dr. Turpin critica o mercantilismo exagerado que acomete a Odontologia e a Medicina em geral, com interesses comerciais sobrepujando os interesses dos pacientes.

Com relação aos tratamentos na dentadura mista, novamente encontra-se um exagero. Vêse uma falta de critério para a determinação de parâmetros de custo-benefício em muitos tratamentos, como se todos os pacientes da faixa etária dos 6-10 anos necessitassem de tratamento até a dentadura permanente. A impressão que se tem é que as crianças nesta idade sofrem de deficiência congênita de monômero de resina acrílica, tal é o número de crianças que "precisam" de tratamento, 
com uma miríade de opções e justificativas para tal. Seguidor dos preceitos de McNamara, sou defensor do tratamento em duas fases, mas com critérios de exclusão dos pacientes que podem ser melhor tratados em uma única fase, ou mesmo os que não precisam de nenhum tratamento, além do acompanhamento. Infelizmente, num país sem nenhum controle regulador do número de cirurgiões-dentistas, com um número de faculdades que poderia suprir a demanda da América do Norte inteira e grande parte da Europa, muitas vezes as decisões dos profissionais são baseadas mais em suas necessidades de fluxo de caixa do que no melhor interesse do paciente.

A o quê, ou a quem, atribuir este estado das coisas? Não sei se é o principal fator, mas o número de cirurgiões-dentistas, a indústria dos mestrados profissionalizantes e o descontrole do número de cursos de "atualização" ou "especialização" sem a mínima condição de funcionamento certamente têm seu quinhão de culpa. Da mesma forma que quem cola um braquete se intitula ortodontista, quem sabe usar o Powerpoint $t^{\circledR}$ se proclama mestre, reforçando o adágio que diz que "quem sabe faz; quem não sabe ensina...". Tristes trópicos estes, em que o esforço de uma formação sólida em tempo integral de 3 anos - de um mestrado como eu e muitos tivemos o privilégio de ter - vale o mesmo que "trinta dinheiros" pagos nos mestrados virtuais ou de carga horária insuficiente.

A resposta às duas indagações se resume em falta de educação ortodôntica adequada e princípios éticos, que nos diferenciem da barbárie que assola a busca pelo lucro a qualquer preço.

8) Nestes anos de experiência clínica, em alto padrão, quais os recursos biomecânicos que você utiliza para o alcance de uma excelente oclusão dentária? Julio Wilson Vigorito

Prezado professor Vigorito, saiba que meus primeiros passos na Ortodontia foram baseados em um livro sobre mecânica Edgewise de sua autoria, e creio que muitos outros ortodontistas possam lhe creditar o mesmo. Para mim, é motivo de lisonja ter como entrevistador o chefe de uma das melhores pós-graduações da América Latina. Minha conduta é a utilização da mecânica Straight-wire associada aos princípios da Mecânica Segmentada de Burstone e os arcos base de Ricketts. A mecânica Straight-wire é excelente para a fase de finalização dos casos, mas é contraproducente nos estágios iniciais. Muitas vezes, casos fáceis podem se tornar mais complexos, apenas em função dos efeitos secundários de uma mecânica mal planejada e conduzida. Seguindo os preceitos desta visão, utilizamos braquetes Straight-wire e fazemos o planejamento mecânico do caso nos preceitos da Mecânica Segmentada. Em função de suas posições no arco dentário e do volume de suas raízes, os dentes de referência são os primeiros molares permanentes, os caninos e os incisivos centrais superiores. Se algum destes dentes estiver mal posicionado, ele deve ser corrigido, inicialmente, com recursos da Mecânica Segmentada, como barras transpalatinas, arcos linguais, overlay (sobrefios); cantilevers, alças retangulares, elásticos, microparafusos, etc (Fig. 9). À medida que estes dentes são conduzidos mais próximos de suas posições adequadas, entram em ação os fios superelásticos, para promover um alinhamento e nivelamento adequado e rápido, uma vez que o fio não precisa defletir muito para atingir seu intento. A grande vantagem desta estratégia é que os dentes que estão bem posicionados não são afetados pelos efeitos secundários da mecânica, como é comum ver em casos em que os fios superelásticos são amarrados a todos os dentes, indiscriminadamente. Muitos ortodontistas observam até uma perda da intercuspidação original que o paciente apresenta, conforme o alinhamento e nivelamento progridem. Não considero isto adequado, uma vez que, muitas vezes, esta relação oclusal não será fácil de ser reconquistada, possivelmente à custa do uso de elásticos de intercuspidação. A ilusão de que o controle tridimensional colocado nos braquetes irá automaticamente levar os dentes às suas posições ideais não se sustenta, uma vez que a variabilidade nas relações esqueléticas e dentárias nos três planos do espaço, associada a morfologias dentárias também variáveis, impede, 

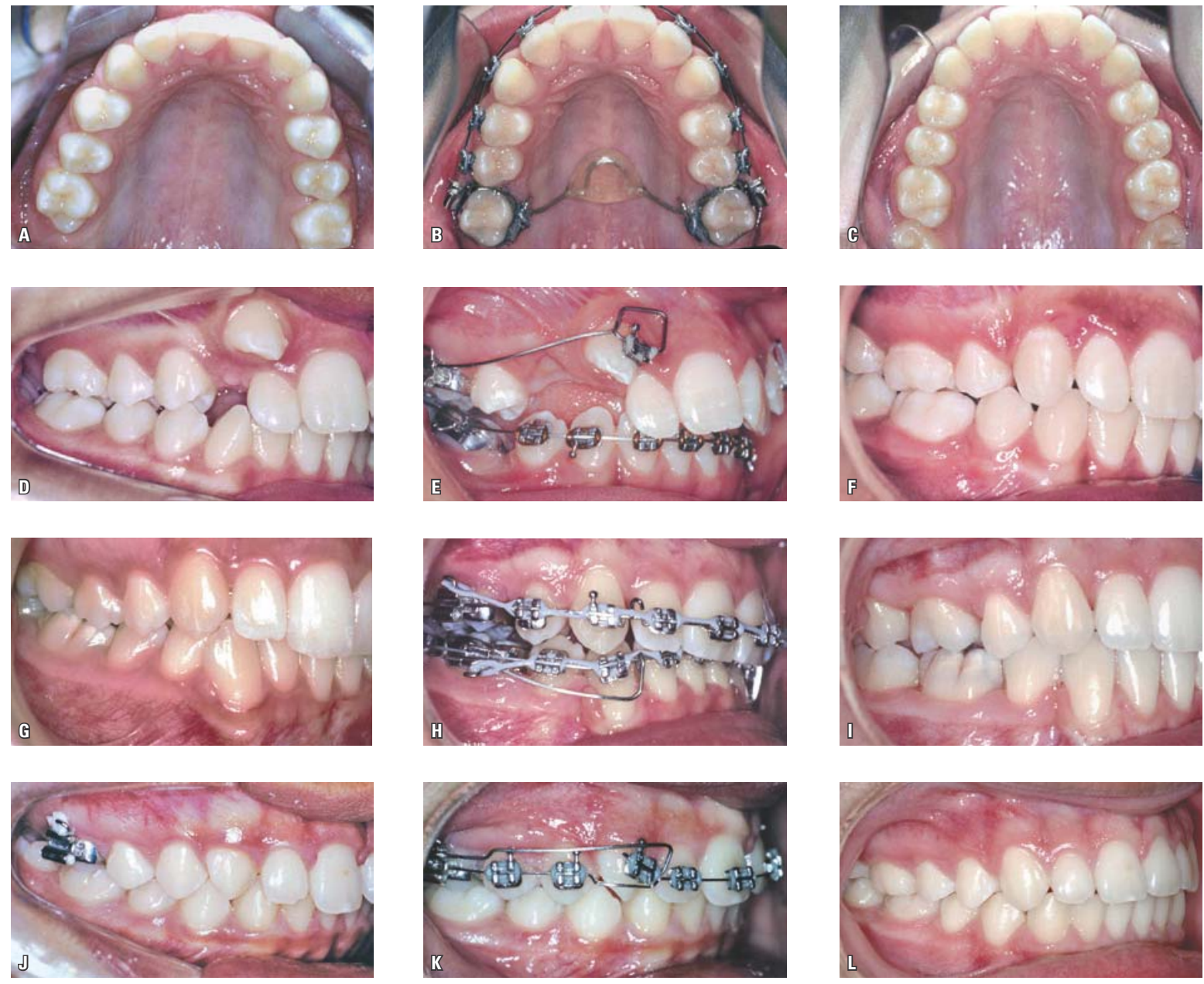

FIGURA 9 - A, B, C) Barra transpalatina; D, E, F) alça retangular; G, H, I) cantilever para controle vertical; J, K, L) sobrefio e alça retangular.

na maioria dos casos, que isto aconteça. Em função destes fatores, somados às deficiências inerentes a todos os sistemas atuais, ainda é necessário que o ortodontista faça ajustes no fio ortodôntico, para obter controle adequado das posições dentárias durante todo o tratamento.

\section{9) Acerca da estabilidade pós-tratamento,} o que você têm a dizer? Julio Wilson Vigorito

A estabilidade pós-tratamento realmente é a grande interrogação de qualquer tratamento que altere a relação oclusal de uma má oclusão que, na maioria das vezes, apresenta algum equilíbrio funcional. As alterações que podem ocorrer após a remoção dos aparelhos ortodônticos são de três naturezas: 1) relacionadas a movimentações ortodônticas inadequadas, do tratamento propriamente dito, 2) recidivas às posições originais que os dentes apresentavam antes da instituição do tratamento e 3) alterações decorrentes do envelhecimento do indivíduo. A primeira, geralmente, ocorre ainda na presença das contenções removíveis; a segunda no primeiro ano após a interrupção do uso dos contentores e a última após alguns anos do término da fase de contenção. Obviamente, nossa responsabilidade se resume às duas primeiras, que estão ligadas ao tratamento propriamente dito, e os pacientes devem ser orientados com relação a esta possibilidade. Já as alterações decorrentes do envelhecimento, como a diminuição progressiva 
das dimensões dos arcos, fogem de nosso controle e a única possibilidade de estabilidade total são as contenções usadas indefinidamente. Acredito que todos os preceitos advindos das pesquisas nesta área, principalmente da Universidade de Washington, são extremamente válidos e atuais, e devem ser considerados quando no planejamento do tratamento propriamente dito e das contenções a serem utilizadas. A manutenção das dimensões da distância intercaninos, por exemplo, embora confundida como dogma por alguns, ainda se mantém como um dos parâmetros da busca por uma melhor estabilidade, e não da estabilidade absoluta, impossível em seres humanos vivos e "mastigantes". Algumas pré-condições são mais favoráveis à estabilidade, como: 1) a obtenção de uma oclusão estática e funcionalmente adequada, respeitando os princípios de uma oclusão mutuamente protegida, com uma oclusão adequada e a mandíbula em relação cêntrica; 2) contatos oclusais adequados em todos os dentes, até nos segundos molares; 3) perfeito paralelismo radicular e nivelamento das cristas marginais; 4) respiração predominantemente nasal, com selamento labial passivo e 5) o paciente se encontrar na fase final do surto de crescimento pubescente ou já sem crescimento. Apesar destes cuidados, algumas condições requerem algo mais que as tradicionais contenções utilizadas pela maioria dos ortodontistas (a placa de Hawley superior e inferior ou o fio colado de canino a canino - 3x3). Dentes com apinhamento exagerado, giroversões e/ou diastemas necessitam de cuidados maiores, principalmente se estiverem na região estética do arco dentário. Muitas vezes é necessária a realização de fibrotomias supracrestais, nos dentes mal posicionados que estejam em áreas estéticas, e de contenções com fios de multifilamentos trançados, colados na face lingual de todos os dentes, normalmente de incisivo lateral a incisivo lateral ou de canino a canino. Finalmente, cabe aqui uma consideração sobre o papel dos terceiros molares, que embora tenha sido demonstrado amplamente na literatura como sendo secundário no apinhamento terciário, "pode não ser uma boa causa do apinhamento, mas é uma boa desculpa...”. Em função do apinhamento terciário e das recidivas ocorrerem na mesma faixa etária, aproximadamente na época de erupção dos terceiros molares, eles são os "suspeitos costumazes", parafraseando a antológica frase do filme Casablanca. Assim, são atribuídas a eles muitas alterações oclusais que não participam de forma significante. Por outro lado, os pacientes adolescentes só devem receber "alta" do tratamento ortodôntico após a solução dos terceiros molares, poupando assim, muitas vezes, que o paciente tenha que realizar extrações traumáticas na idade adulta. Mesmo que irrompidos ou em condições de erupção adequadas, terceiros molares localizados no corpo da mandíbula, normalmente, estão numa região de mucosa, com prognóstico periodontal ruim de manutenção a longo prazo.

10) Considerando suas recentes e significativas mudanças, o que você eliminou e o que você acrescentou na sua conduta clínica, que poderia dividir com os leitores da Dental Press, que o tem como referência de atualidade e qualidade na Ortodontia? Roberto Brandão

Agradeço suas palavras elogiosas inseridas na pergunta, mas, sem falsa modéstia, não me considero referência na Ortodontia, a não ser na preocupação constante em melhorar como clínico, pessoa humana, como esposo e pai. O que mais recentemente acrescentei à minha conduta clínica foram 4 novos aspectos, mecânicos e administrativos. O primeiro é o uso de braquetes auto-ligáveis, em praticamente $75 \%$ dos casos iniciados a partir de junho de 2006. Acredito que o sistema auto-ligável não é apenas o futuro, mas, se mudarmos nossos paradigmas de relação custo/benefício, eles já são o presente, para um número cada vez maior de ortodontistas. Hoje praticamente todos os grandes e médios fabricantes de materiais ortodônticos desenvolveram seu próprio sistema, o que ficou cristalizado no último congresso de Ortodontia da $\mathrm{AAO}$, em Seattle. As vantagens destes braquetes, ainda que não em suas versões ideais, se mostrarão àqueles que os utilizarem de maneira rotineira, alterando 
o panorama de como fazemos Ortodontia atualmente no Brasil. Paralelamente, mudei o sistema de pagamento, utilizando o preço fechado, negociado com o paciente, permitindo-lhe a escolha de uma entre algumas opções pré-elaboradas, seguindo a forma de pagamento efetuada nos Estados Unidos. A terceira mudança recente foi no agendamento dos retornos, que passei de 4 semanas para 6 ou 8 semanas, mesmo em pacientes com braquetes não auto-ligáveis. Obviamente, tantas mudanças geram algum desconforto e adaptações, mas é uma mudança sem volta e que faz todo o sentido, numa época de braquetes auto-ligáveis e fios superelásticos. Meu planejamento e mecânica continuam iguais, só que associados a esta nova tecnologia. $\mathrm{O}$ quarto e último acréscimo, que está em processo de desenvolvimento, deriva-se de um conceito do Dr. Kleber Meireles, de Salvador/BA, composto por um conjunto de acessórios a serem utilizados quando na movimentação ortodôntica estiver indicado um movimento de corpo das unidades ativas, podendo ser usado ou não associado a dispositivos

\section{REFERÊNCIAS}

1. ARAUJO, A.; BUSCHANG, P.; MELO, A. C. Adaptative condilar growth and mandibular remodelling changes with Bionator therapy - an implant study. Eur. J. Orthod., Oxford, v. 26, no. 5, p. 515-522, 2004

2. CHAGAS, R.; ASSIS, C.; ALMEIDA, G.; URSI, W. Alterações dimensionais maxilares provocadas por expansor colado, com dois padrões de ativação. Rev. Dental Press Ortodon. Ortop. Facial, Maringá, v. 6, n. 3, p. 36-47, maio/ jun. 2001.

3. CORBETT, C. K. et al. Long term profile changes in extraction and non-extraction patients. Am. J. Orthod. Dentofacial Orthop., St. Louis, v. 128, no. 4, p. 450-457, Oct. 2005.

4. MCNAMARA, J. A.; BRUDON, W. Orthodontic and orthopedic treatment in the mixed dentition. Needham Press: Ann Arbor, 1993.

5. PANCHERZ, H. History, background and development of the Herbst appliance. Semin. Orthod., Philadelphia, v. 9, p. 3-11, 2003.

6. RUF, S.; PANCHERZ, H. When is the ideal period for Herbst therapy: early or late? Semin. Orthod., Philadelphia, v. 9, p. 47-56, 2003.

7. STEPHENS, $C . K$. et al Long-term profile changes in extraction and nonextraction patients. Am. J. Orthod. Dentofacial Orthop., St. Louis, v. 128, no. 4, p. 450-457, Oct. 2005.

8. VIG, R. G.; BRUNDO, G. C. The kinetics of tooth display. J. Prosthet. Dent., St. Louis, v. 39, no. 5, p. 502-504, 1978. de ancoragem temporária (miniparafusos, miniplacas, etc). Este sistema, com um embasamento biomecânico sólido, merecerá agora um investimento na implementação da sua fabricação em escala, o que permitirá o acesso a quem se interessar por uma mecânica com menores efeitos secundários.

\section{Agradecimentos}

Agradeço à professora Telma Martins de Araújo, pela edição e sugestões realizadas no texto, que contribuíram de forma substancial na apresentação final desta entrevista.

\footnotetext{
Alexandre Moro

- Mestre em Ortodontia pela UMESP.

- Doutor em Ortodontia pela USP - Faculdade de Odontologia de Bauru.

- Professor do Departamento de Anatomia da UFPR.

- Professor da Disciplina de Odontologia da Infância do UNICENP.

- Professor dos Cursos de Especialização em Ortodontia da UFPR e do UNICENP.
}

\section{Guilherme Janson}

- Professor Titular do Departamento de Ortodontia da FOBUSP.

- Chefe do Departamento de Odontopediatria, Ortodontia e Saúde Coletiva da FOB-USP.

- Coordenador do curso de Mestrado de Ortodontia da FOBUSP.

- Pós-doutorado em Toronto - Canadá.

\section{Júlio Wilson Vigorito}

- Professor Titular da disciplina de Ortodontia, Departamento de Ortodontia e Odontopediatria da FOUSP.

- Coordenador do Programa de Pós-Graduação em Ortodontia (Mestrado e Doutorado) da FOUSP.

- Autor do livro "Ortodontia clínica: diagnóstico e terapêuticas".

\section{Roberto Carlos Bodart Brandão}

- Mestre em Ortodontia pela UFRJ.

- Doutor em Ortododntia pela UNESP-Araraquara.

- Professor Adjunto de Ortodontia da UFES.

- Diplomado pelo Board Brasilerio de Ortodontia (BBO). 